\title{
PROFESSORES INICIANTES: ACOLHIMENTO E CONDIÇÕES DE TRABALHO
}

\section{BEGINNERS TEACHERS: RECEPTION AND WORKING CONDITIONS}

\author{
GABARDO, Cláudia Valéria \\ claudiagabardo@uol.com.br \\ Universidade da Região de Joinville \\ HOBOLD, Márcia de Souza \\ marcia.hobold@univille.br \\ Universidade da Região de Joinville
}

\begin{abstract}
RESUMO A fase de iniciação profissional docente é um momento de grande importância na constituição da carreira do professor e da sua identidade. O processo de inserção de professores iniciantes tem se constituído em um momento de suma importância na carreira do professor, não apenas por ser um período de adaptação à profissão docente, mas, sobretudo, pelas implicações dele decorrentes. Nesse processo, se a recepção e integração com os pares e as condições de trabalho não forem adequadas, a tendência é potencializar as possíveis dificuldades enfrentadas pelos professores em início de carreira, podendo causar desconforto e sofrimento. Com o objetivo de conhecer como se dá o acolhimento e as condições de trabalho aos professores iniciantes, esta pesquisa teve como sujeitos professores com até três anos de ingresso na Rede Municipal de Ensino, independente da formação, idade e sexo. Diante da quantidade elevada de sujeitos e por se tratar de um levantamento de dados, compreende-se que esta pesquisa articula-se ao tipo survey. Assim, os sujeitos envolvidos foram "ouvidos" através de questionário préelaborado, com perguntas abertas e fechadas. Teoricamente, este estudo referenciase em Marcelo (1992 e 1999), Nóvoa (1992) e Huberman (1989, 1992 e 1995), entre outros. Por meio dos dados coletados, percebeu-se que se o ambiente e as condições de trabalho não forem adequados, a tendência é potencializar as possíveis dificuldades enfrentadas pelos professores em início de carreira, podendo causar desconforto e sofrimento, desencadeando, inclusive, a vontade de deixar a profissão. Ou seja, as dificuldades dos professores iniciantes estão intrinsecamente ligadas às suas condições de trabalho, as quais influenciam diretamente nas suas vidas e nos resultados almejados como profissionais.
\end{abstract}

PALAVRAS-CHAVE: Trabalho docente. Início da docência. Ensino fundamental.

ABSTRACT The phase of starting in the teaching career is a moment of great importance to the teacher's career and his identity. The process of inserting beginning teachers in their jobs is a moment of fundamental importance in the career 
of the teacher not only because it is a time of adaptation to the teaching profession, but mostly because of the resulting implications. In this process, if the welcoming and the integration with their peers and the work conditions are not adequate, the tendency is the increase of possible difficulties faced by teachers who start their careers what may cause discomfort and suffering. With the objectives of knowing how the welcoming of the new teachers happens and of having a better picture of their work conditions, this research was focused on starting teachers who were employed by the Joinville Municipal School system. In order to know how is the host and working conditions for beginning teachers, this study was subject beginning teachers to three years of entry into the municipal schools, regardless of education, age and sex. Due to the high quantity of researched subjects and since it focused on a data survey, this research relates to a "survey" type. Therefore, the subjects of the research were heard through a pre developed questionnaire with open and closed questions. Theoretically this study was based on Marcelo (1992 and 1999), Nóvoa (1992) and Huberman (1989, 1992 and 1995), among others. Through the collected data, it was possible to notice that, if the environment and the working conditions are not adequate, the tendency is the increase of possible difficulties faced by teachers in the beginning of their careers, what may cause discomfort and suffering, which may lead the teacher to quit this profession. In other words, the difficulties faced by starting teachers are intrinsically linked to their working conditions which impact their lives directly as well as the results they expect to obtain as professionals.

KEYWORDS: Teaching practice. Beginning of the teaching. Elementary and middle school teachers.

\section{INTRODUÇÃO}

O período inicial da profissão docente é um momento de grande importância na constituição da carreira do professor e da sua identidade. Esse momento tem sido reconhecido por suas características próprias e configurado pela ocorrência das principais marcas da identidade que engendram a profissionalidade docente. A fase inicial de inserção na docência é a passagem de estudante a professor, a qual teve início nas atividades de estágio e prática de ensino. De acordo com Marcelo Garcia ${ }^{1}$ (1999, p.113), "os primeiros anos de ensino são especialmente importantes porque os professores devem fazer a transição de estudantes para professores e, por isso, surgem dúvidas, tensões [...]". Se por um lado o início de carreira docente é importante, por outro é um período difícil, onde o professor experiencia novos papéis e se depara com inúmeros desafios, tais como a organização das atividades em sala de aula, o relacionamento com os estudantes e com os próprios colegas

\footnotetext{
${ }^{1}$ Neste artigo, o autor Carlos Marcelo Garcia será referenciado como Marcelo Garcia, respeitando a forma de citação que o próprio autor utiliza em seus textos.
} 
professores, gestores e familiares.

A entrada na carreira, de acordo com Tardif (2002, p. 11), “[...] é um período realmente importante na história profissional do professor, determinando inclusive seu futuro e sua relação com o trabalho". As primeiras experiências vivenciadas pelos professores em início de carreira têm influência direta sobre a sua decisão de continuar ou não na profissão, porque este é um período marcado por sentimentos contraditórios que desafiam cotidianamente o professor e sua prática docente.

Para Cavaco (1993, p. 114), "os primeiros anos parecem efetivamente deixar marcas profundas na maneira como se pratica a profissão". Além disso, o período inicial da carreira é fundamental, porque um fracasso nesta fase parece levar à desvalorização pessoal, enquanto o mesmo fracasso, ocorrido alguns anos mais tarde, será, provavelmente, apenas vivenciado como um episódio profissional que precisa ser reelaborado.

Pesquisadores como Marcelo Garcia (1999), Cavaco (1993) e Tardif (2002), consideram o início da carreira como o período potencialmente problemático, tendo em vista as implicações que esta fase tem para o futuro profissional do professor em termos de autoconfiança, experiência e de identidade profissional. Considera-se que é nos primeiros anos de prática profissional que o professor desenvolve o seu estilo pessoal de trabalho.

Para descrever a dificuldade ou os desafios dos professores no início da carreira, Veenman (1984) tem utilizado o conceito de choque com a realidade, procurando descrever a situação de discrepância entre as expectativas que os novos profissionais possuem e a realidade do trabalho que realizam.

Huberman (1992) também faz referência à expressão "choque com a realidade", ao reconhecer que a iniciação na docência é um período de aprendizagens intensas que pode traumatizar e despertar no professor a necessidade de sobreviver aos desafios da profissão. Em outro estudo, (HUBERMAN, 1995) complementa que, além do choque com a realidade, outros desafios fazem parte dessa etapa: a sobrevivência e a descoberta. A descoberta contribui para que o professor sobreviva à fase inicial da docência. Para o autor, é a descoberta que ameniza as dificuldades, pois "o entusiasmo inicial, a exaltação por estar, finalmente, em situação de responsabilidade (ter a sua sala de aula, os seus alunos, o seu programa), por se sentir num determinado corpo profissional" 
(HUBERMAN, 1995, p.39) são elementos que servem de motivação e fazem com que os professores iniciantes sobrevivam a esse momento. A descoberta dos meandros da profissão é que contribui para a permanência na docência.

Considerando estas indicações teóricas, o presente artigo apresenta dados de uma pesquisa que tem como objetivo conhecer como se dá o acolhimento e as condições de trabalho aos professores iniciantes do ensino fundamental, sobre seu início de carreira na rede pública de ensino. O processo de inserção de professores iniciantes tem se constituído em um momento de suma importância na carreira do professor, não apenas por ser um período de adaptação à profissão docente, mas, sobretudo, pelas implicações deles decorrentes. Nesse processo, se o ambiente e as condições de trabalho não forem adequados, a tendência é potencializar as possíveis dificuldades enfrentadas pelos professores em início de carreira, podendo causar desconforto e sofrimento, desencadeando, inclusive, a vontade de deixar a profissão.

\section{O INÍCIO DA DOCÊNCIA: APORTES TEÓRICOS}

Apesar do aumento do número de pesquisas que envolvem a temática acerca do ingresso na profissão docente nos últimos anos, ainda é pequena a parcela de trabalhos realizados sobre o assunto. Tais trabalhos abordam diferentes aspectos, que vão desde as dificuldades encontradas até a relação teoria e prática, destacando como os professores desenvolvem seus conhecimentos e como lidam com os problemas ao deixarem de ser alunos para serem professores (GUARNIERI, 1996; MONTEIRO VIEIRA, 2002).

Alguns autores como Huberman (1992), Veenman (1984), Marcelo (1992 e 1999) e Gonçalves (1192) trazem à tona o conceito de desenvolvimento profissional e da noção de ciclos profissionais. Estes autores investigam o que seriam "níveis de desenvolvimento do professor", e que é "[...] a partir deles que se delineiam as investigações sobre esse tipo de professor (iniciante), procurando abarcar vários aspectos dessa transição [...]" (GUARNIERI, 1996, p.12).

Huberman (1989) realizou um dos mais referenciados estudos do desenvolvimento profissional dos professores. Ele procurou analisar, entre outros tópicos, a existência de fases comuns aos diversos professores, os melhores e 
piores momentos do ciclo profissional. O autor concluiu que há diversas constantes ou itinerários-tipo que caracterizam o percurso profissional de certos grupos de professores e cada um destes grupos é caracterizado por sequências específicas de desenvolvimento profissional ao longo das cinco fases que distinguiu na carreira docente: exploração, estabilização, dinamismo, conservadorismo e desinvestimento.

Seus estudos sobre o desenvolvimento da carreira docente permitem identificar como se caracteriza o ciclo de vida dos professores. De acordo com o autor, o professor passa por uma fase de sobrevivência e descoberta ao iniciar seu percurso profissional, avançando, gradativamente, para uma fase de estabilização, quando começa a tomar uma maior consciência do seu papel. Este ciclo, conforme o autor, não se constitui em etapas fixas, mas sim num processo dinâmico e bem peculiar (HUBERMAN, 1992).

Vale ressaltar que o olhar desta pesquisa está direcionado para a fase de exploração, ou seja, os primeiros anos de docência que contribuem para a constituição da profissionalidade do professor.

Marcelo Garcia (1992, 1999) muito contribui para a discussão da fase inicial na docência. Em suas pesquisas, faz importantes considerações sobre os desafios, angústias, descobertas e aprendizagens da iniciação nesta atividade profissional. Para o autor:

[...] o ajuste dos professores a sua nova profissão depende [...] das experiências biográficas anteriores, dos seus modelos de imitação anteriores, da organização burocrática em que se encontra inserido desde o primeiro momento da sua vida profissional, dos colegas e do meio em que iniciou a sua carreira docente. (MARCELO GARCIA, 1999, p.118).

Isso quer dizer que os professores já trazem consigo muitas experiências sobre o ser professor, desde a sua trajetória como estudante, nas séries anteriores à formação inicial, bem como as novas vivências culturais que se engendram no espaço escolar e na interação com os colegas professores e estudantes.

As primeiras experiências vivenciadas pelos professores em início de carreira têm influência direta sobre a sua decisão de continuar ou não na profissão, porque este é um período marcado por sentimentos contraditórios, que desafiam cotidianamente o professor e sua prática docente. Esta fase é também marcada por intensas aprendizagens que possibilitam ao professor a sobrevivência na profissão 
(MARCELO, 1992; CAVACO, 1995; LIMA, 2006).

Discutir o início da carreira docente perpassa pela discussão de um campo maior: a formação de professores. De acordo com Romanowski (2012), para os professores iniciantes, a formação ganha relevância, pois é um período de aprendizado profissional e pessoal. Sem uma adequada formação, os professores terão maior dificuldade para desenvolver seu trabalho pedagógico. Daí a necessidade de programas de formação continuada que visem proporcionar novas aprendizagens e interlocuções desses profissionais. Em se tratando do período inicial da carreira dos professores, essas preocupações se acentuam em razão de que as instituições formadoras e os sistemas de ensino, em sua maioria, não dão a devida atenção a essa etapa da vida profissional.

\section{PERCURSO METODOLÓGICO}

A presente pesquisa delineou-se por meio da abordagem qualitativa. Gatti e André (2010, p. 30) afirmam que as pesquisas chamadas qualitativas:

[...] vieram a se constituir em uma modalidade investigativa que se consolidou para responder ao desafio da compreensão dos aspectos formadores/formantes do humano, de suas relações e construções culturais, em suas dimensões grupais, comunitárias ou pessoais. Essa modalidade de pesquisa veio com a proposição de ruptura do círculo protetor que separa pesquisado e pesquisador, separação que era garantida por um método rígido e pela clara definição de um objeto, condição em que o pesquisador assume a posição de 'cientista', daquele que sabe, e os pesquisados se tornam dados - por seus comportamentos, suas respostas, falas, discursos, narrativas etc. traduzidas em classificações rígidas ou números-, numa posição de impessoalidade. Passa-se a advogar, na nova perspectiva, a não neutralidade, a integração contextual e a compreensão de significados nas dinâmicas histórico-relacionais.

Neste estudo, o local escolhido para se investigar o início da docência foi a Rede Municipal de Ensino. Os sujeitos participantes desta pesquisa são professores do Ensino Fundamental, efetivos na rede, independente da idade, sexo e carga horária. O número total de docentes foi obtido mediante informações concedidas pela Secretaria Municipal de Educação. Assim, foram convidados todos os professores concursados que ingressaram na rede pública municipal de ensino entre os anos de 2009 e 2011, isto é, com até três anos de experiência profissional. Esse tempo de ingresso foi definido pelo fato de que os professores se encontravam na 
fase de exploração, descrita por Huberman (1995). Os professores sujeitos desta pesquisa estavam alocados em 66 unidades escolares da rede, todas na área urbana do município.

Pela temática de estudo desta pesquisa, fez-se necessário desenvolver um instrumento que possibilitasse descrever, explicar e explorar as questões apresentadas. Assim, o instrumento escolhido para a coleta de dados foi $o$ questionário. A opção pelo questionário deu-se em função do número de professores iniciantes da rede e por estarem eles alocados em várias escolas, sem saber ao certo onde.

Em consulta preliminar, a Secretaria Municipal de Educação informou que 199 professores $^{2}$ ingressaram na rede entre 2009 e 2011, um número significativo de sujeitos a serem investigados. Assim, a amplitude da pesquisa tornou-se evidente e o questionário apresentou-se como a alternativa mais adequada para a condução da pesquisa.

O questionário, segundo Marconi e Lakatos (2003, p.201), é um "instrumento [...] constituído por uma série ordenada de perguntas, que devem ter respostas por escrito e sem a presença do entrevistador". Para a obtenção dos dados deste estudo, o questionário foi organizado de forma autoaplicável, sendo composto por 26 perguntas, das quais 18 fechadas e 08 abertas. De acordo com Severino (2008, p.125), questões abertas são aquelas as quais "o sujeito pode elaborar as respostas, com suas próprias palavras, a partir de sua elaboração pessoal" e as fechadas, aquelas em que "[...] as respostas serão escolhidas dentre as opções predefinidas pelo pesquisador". Vale ressaltar que a opção pelas perguntas abertas deu-se pela necessidade de "ouvir" o que os professores iniciantes tinham a dizer sobre o seu ingresso na docência.

Diante da quantidade elevada de questionários e por se tratar de uma pesquisa de levantamento/mapeamento que tem por objetivo conhecer uma determinada situação, compreende-se que este estudo articula-se ao tipo survey. Segundo May (2004, p. 109),

As surveys são um dos métodos empregados com mais frequência na pesquisa social e são utilizadas igualmente pelo governo, pelos

\footnotetext{
${ }^{2}$ Dado fornecido pela Secretaria Municipal de Educação de Joinville em outubro de 2011.

3 A palavra "vozes", neste contexto, é entendida como o espaço proporcionado para que os professores falassem, por meio da linguagem escrita, sobre o início da docência.
} 
pesquisadores acadêmicos nas universidades e pelas organizações militares. Quase todas se caracterizam pela coleta de dados referentes a um grande ou muito grande número de pessoas.

Para o autor, as pesquisas surveys são processos de coleta de informações sobre sujeitos que constituem uma população real, também denominada de levantamento amostral.

Freitas (2000) diz que a pesquisa de método survey destaca-se por propor uma investigação que vise responder a questionamentos acerca do que acontece, quais as possíveis razões e implicações que o objeto de estudo possui dentro do contexto no qual está inserido.

Seguindo os critérios propostos por May (2004), o questionário foi, ainda, estruturado com um breve cabeçalho contendo as principais informações a respeito da pesquisa, esclarecimentos sobre quem seriam os respondentes, e sobre o caráter voluntário dos participantes. Também foi enviada uma carta explicando a natureza da pesquisa, a sua importância e a necessidade de se obterem respostas, tentando despertar o interesse do professor no sentido de que ele preenchesse e devolvesse o questionário.

De posse dos questionários devolvidos, iniciou-se a leitura das respostas e a separação dos documentos preenchidos e dos entregues em branco, constatandose quais dos sujeitos estavam dentro dos critérios de inclusão. Desse modo, obtiveram-se dois grupos: os "válidos" e os "não válidos". Importante destacar que dos 199 questionários entregues, 112 retornaram respondidos; sendo que 04 estavam em branco e 103 foram considerados válidos porque os professores tinham até três anos de ingresso na carreira docente. Os outros 83 questionários não foram devolvidos.

Para a análise das respostas obtidas foram utilizadas planilhas do programa Excel. Dessas planilhas foram gerados os gráficos para melhor visualização dos dados. Por meio desse procedimento obteve-se o perfil dos professores respondentes. Com relação às perguntas abertas, num total de oito, juntamente com alguns comentários das perguntas fechadas, o procedimento se repetiu utilizandose, novamente, a planilha no Excel.

Assim, iniciou-se a análise de conteúdo das respostas. Segundo Franco (2005, p. 13), 
A análise de conteúdo trabalha tradicionalmente com materiais textuais escritos [...] o ponto de partida é a mensagem, mas deve ser considerado as condições contextuais de seus produtores e assenta-se na concepção crítica e dinâmica da linguagem.

Portanto, na análise de conteúdo deve ser considerada não apenas a semântica da língua, mas também a interpretação do sentido que um indivíduo atribui às mensagens. A finalidade da análise de conteúdo é produzir inferência, trabalhando com vestígios e índices postos em evidência.

Para categorizar as falas dos professores respondentes, foram consideradas a recorrência das respostas, a contradição e a complementaridade (FRANCO, 2005). As categorias foram devidamente denominadas para tornar possível a organização dos dados.

\section{ACOLHIMENTO E CONDIÇÕES PARA O INÍCIO DA DOCÊNCIA}

Assumir a função de professor no magistério, público ou privado, é um processo marcado por inseguranças, medos, decepções, impactos, dificuldades, mas também por intensas aprendizagens, alegrias, conquistas e superações.

Para descrever a dificuldade ou os desafios dos professores no início da carreira, Veenman (1984) tem utilizado a expressão choque com a realidade, procurando descrever a situação de discrepância entre as expectativas que os novos profissionais possuem e a realidade do trabalho que realizam. $\mathrm{O}$ autor constatou, em sua pesquisa, que os professores iniciantes defrontam-se com a realidade das escolas e questionam os "ideais missionários" construídos durante a sua formação inicial.

Huberman (1992) também faz referência à expressão, ao reconhecer que a iniciação na docência é um período de aprendizagens intensas, que pode traumatizar e despertar no professor à necessidade de sobreviver aos desafios da profissão. Em outro estudo, (HUBERMAN, 1995) complementa que, além do choque com a realidade, outros desafios fazem parte dessa etapa: a sobrevivência e a descoberta. A descoberta contribui para que o professor sobreviva à fase inicial da docência.

Este impacto com a realidade escolar leva os docentes a ressignificar sua 
prática de trabalho, tendo em vista a melhoria das suas ações em sala de aula. Ainda, nesse período, os professores vão estabelecer interações com outros agentes da comunidade escolar (supervisores, orientadores, diretores, professores), e fora dela (familiares, colegas de profissão de outras escolas e dos espaços de formação acadêmica), construindo algumas lógicas importantes que poderão tornarse definitivas para suas ações docentes.

Assim, ao ser perguntado aos professores pesquisados quais ações sugeririam para que os professores iniciantes se sentissem mais acolhidos, a recepção e integração com os novos pares foram as sugestões que mais ficaram evidenciadas, aparecendo em 54 respostas, equivalente a 52\%. Muitos professores afirmaram que esta prática já vem sendo realizada pelas unidades escolares, como pode ser observado:

Espero que sejam acolhidos como eu fui um dia, por uma escola de portas abertas com gestores acessíveis e um grupo de trabalho focado na educação. (P31)

Serem acolhidos com uma integração, onde sejam colocadas todas as informações sobre o sistema de trabalho e o regimento. (P42)

Segundo os respondentes, a "acolhedora" recepção pela rede está vinculada, principalmente, à figura do supervisor de ensino que, segundo a Secretaria de Educação ${ }^{4}$, é o profissional responsável em receber e acompanhar os professores ingressantes durante e após o estágio probatório.

No primeiro momento é importante o que já acontece na maioria das escolas, a recepção realizada pela equipe administrativa. Em seguida o repasse da supervisão para conhecer a linha de trabalho da escola. E claro, seria interessante nesta etapa a troca de experiências com professores que trabalham no mesmo ano (série) que o professor em que esta ingressando trabalhará. (P11)

Dessa forma o poder público acredita dar o suporte inicial aos novos professores que ingressam na rede. Também afirmam que o supervisor na escola é quem tem o papel de acompanhar, orientar e avaliar este professor, pois é ele o responsável em supervisionar o estágio probatório. Quando detecta problemas com

\footnotetext{
${ }^{4}$ Dados fornecidos pela Secretaria de Educação (2012)
} 
o desempenho do professor iniciante, a escola comunica a Secretaria de Educação que passará a acompanhar o docente; sendo que, somente depois de esgotadas todas as possibilidades de apoio é que o professor iniciante pode ser reprovado no estágio probatório.

Para um bom andamento nesse início de carreira, os iniciantes apontam a necessidade de um acompanhamento sistematizado e intencional, com cursos de formação continuada, palestras, formação de grupos de estudos, "treinamento" na própria escola em que atuam.

Também se percebeu em 13 professores (12\%), a expectativa por ações simples, como, por exemplo, a recepção aos professores iniciantes com paciência, tolerância, simpatia, respeito, motivação e até com "um cafezinho".

Que nos olhem nos olhos e nos vejam como seres humanos sensiveis e com necessidades. Acredito que quando você recebe um bom tratamento da direção, e outros, você repassa isso para os alunos. Todos precisam de carinho e atenção. (P07)

Uma queixa frequente entre as respostas diz respeito aos professores mais experientes os quais, muitas vezes, formam "panelinhas", tendo certo preconceito com quem chega, deixando a impressão que estão ocupando o lugar dos outros. Para os professores pesquisados as contribuições pessoais de colegas mais experientes seriam apoios importantes que os ajudariam a superar os possíveis desconfortos e dificuldades do início da profissão.

O acolhimento aos novos professores parece estar mais relacionado à unidade escolar onde irão atuar, isto é, uma ação mais individual organizada pela equipe gestora, do que à rede de ensino.

Já trabalhei, e percebo sim que está na mão do administrador fazer com que o novo profissional seja bem acolhido. Por duas vezes me senti muito mal ingressar em duas diferentes escolas. (P68)

Por isso, perguntou-se no questionário se o professor iniciante trabalhava em mais de uma escola e se havia diferença de acolhimento entre elas. 68 professores respondentes (66\%) não responderam à questão por atuarem em apenas uma unidade, como pode ser verificado no gráfico apresentado anteriormente. $28 \%$, ou seja, 29 professores, responderam que há diferença de acolhimento entre as escolas e apenas $7 \%$ alegaram não haver distinção. Essas informações são 
apresentadas no gráfico a seguir:

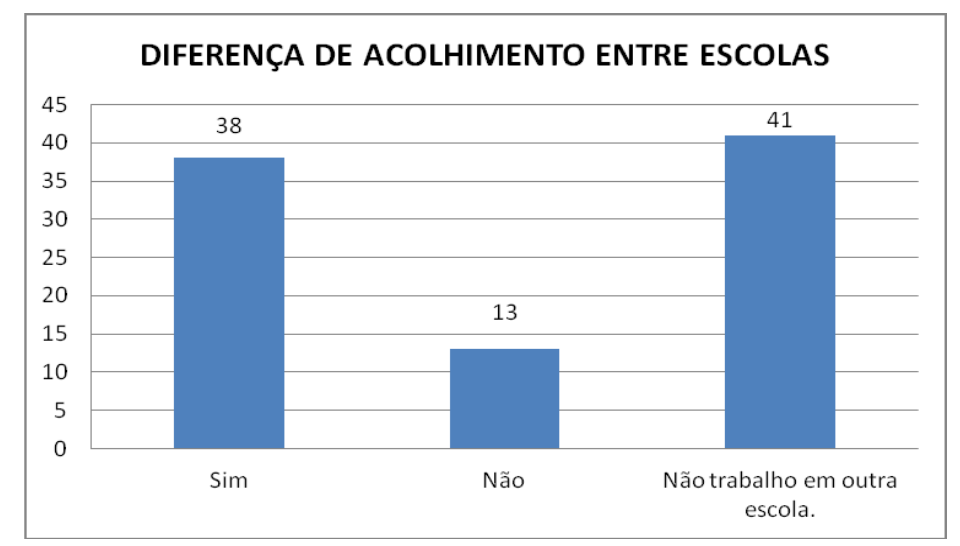

Gráfico 01: Distribuição dos Professores por Número de Escolas em que trabalham Fonte: Questionário da pesquisa "O início da docência no ensino fundamental da Rede Municipal de Ensino" (2011)

Dos respondentes que afirmaram haver diferença, muitos compararam as redes - particular, estadual e municipal - e não as escolas de uma mesma rede. Mesmo assim, é importante ressaltar que, para os professores, a rede particular de ensino acolhe melhor, dá mais orientação, mas há um maior "controle" do fazer pedagógico e de questões administrativas, tais como: faltas do professor, cumprimento do plano de ensino, proposta pedagógica de instituição, índice de reprovação, entre outros.

Com relação à diferença de acolhimento entre as escolas da rede municipal de ensino, os professores acham "normal" haver diferença, uma vez que:

\section{[...] devido à questão cultural de cada grupo. (P55)}

Todo ambiente é diferente, cada escola vive uma realidade, é normal a diferença no acolhimento. (P77)

Para alguns professores pesquisados, as diferenças entre as escolas não dependem apenas de questões culturais, mas também do grupo de profissionais que fazem parte da escola.

Em uma das escolas bem acolhida (apresentação da mesma, grupo etc). Já em outra se vire, conheça por si sozinha. (P81)

Cada escola tem o seu perfil. Uma é mais acolhedora, procura ser sensível a algum problema do profissional. Algumas há mais cobrança sem precisar, depende da escola cabe ao profissional saber lidar com as diferenças. (P79) 
resistência de troca de atividades, o individualismo predomina. Na outra, posso conversar, trocar atividades e realizar atividades juntos. (P30)

Outros professores atribuem estas diferenças não apenas à gestão, mas aos próprios colegas de profissão:

Por parte dos próprios professores, em uma são mais amigos, e dão liberdade para você entrar e fazer parte das conversas etc., já na outra tratam o novato com indiferença, não dão liberdade para você participar. (P83)

Na escola que eu sou efetiva os professores são mais simples embora tenham todos ótimas formações. Na escola que eu tenho termo, os professores são mais fechados. (P90)

Pode-se afirmar que existem diferenças de acolhimento entre uma escola e outra, e que independente dos porquês delas acolherem dessa ou daquela forma, as que acolhem melhor têm professores mais motivados e seguros para realizarem seu trabalho.

Também esteve presente nas respostas dos professores, além da diferença de acolhimento entre uma escola e outra, a questão das diferentes características de cada local, o que denominaram "realidades". Tais diferenças têm base principalmente nas condições socioeconômicas e culturais dos alunos. Outros aspectos como: falta de condições de trabalho (recursos e baixos salários); diferentes concepções dos colegas de trabalho; direção político-ideológica da instituição e atuação da direção e equipe pedagógica foram parâmetros utilizados para caracterizar as "realidades de trabalho" como "melhor" ou "pior".

Geralmente, as "boas realidades" relacionaram-se às escolas que contavam com uma equipe pedagógica colaborativa; que possuíam materiais didáticos e que favoreciam a autonomia dos professores. Os depoimentos dos professores retratam e comprovam que a gestão escolar tem influência direta sobre o acolhimento e condições de trabalho aos professores iniciantes.

A escola depende de pessoas, a escola é feita de pessoas e cada uma com seu comportamento, portanto os ambientes são criados e geridos diferentemente (P31)

As relações interpessoais com outros sujeitos do ambiente escolar, as 
condições objetivas de trabalho nas escolas, as dificuldades enfrentadas no processo de ensino e aprendizagem e com o "domínio" da turma, foram algumas questões apresentadas pelos professores respondentes. Esta última, especialmente, refere-se à capacidade de fazer com que os alunos se interessassem pelas aulas e que isso pudesse mantê-los atentos e disciplinados. No entanto, alguns professores afirmaram terem uma boa relação pessoal com os estudantes.

Se a relação com os alunos durante as aulas foi apontada como uma das dificuldades do trabalho dos professores iniciantes, as relações interpessoais com os colegas de trabalho adquiriram mais relevância e tiveram mais interferência nessas dificuldades. Quando perguntado em quais profissionais os professores iniciantes buscam apoio para as questões inerentes à profissão docente, percebe-se que a equipe administrativa das escolas em que atuam, os diretores e os supervisores, é que dão suporte para os novatos.

Contar com o apoio de pessoas mais experientes parece ser uma das maneiras de amenizar o "choque de realidade", e "sobreviver" a esta etapa descrita como desafiadora. Quando questionados quais profissionais os professores iniciantes consultam sobre as suas necessidades, as respostas focalizaram os supervisores (39\%), a direção da escola (33\%) e os colegas de trabalho (24\%).

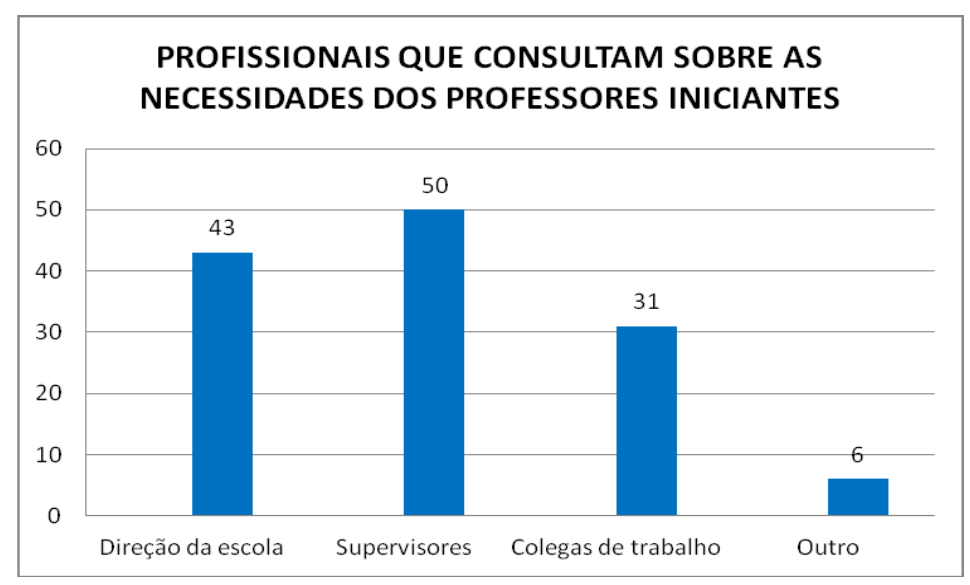

Gráfico 02: Profissionais consultados sobre as necessidades dos professores iniciantes. Fonte: Questionário da pesquisa "O início da docência no ensino fundamental da Rede Municipal de Ensino" (2011)

Novamente os supervisores aparecem como essenciais à etapa de iniciação na docência, não descartando os gestores e colegas de trabalho. Mizukami (2004) considera que a constituição de uma cultura colaborativa nas escolas poderia ajudar 
a superar a situação dilemática em que se encontram os iniciantes, uma vez que o conhecimento que os docentes precisam adquirir deve vir, de certa forma, da análise de experiências com a sua classe, dos trabalhos dos seus estudantes, das observações de aulas feitas por professores mais experientes, de reflexões pessoais e coletivas - fundamentadas em estudos teóricos - sobre as práticas. A colaboração entre os pares é uma forma de apoio que os iniciantes valorizam e precisam.

As primeiras experiências na profissão docente estão ligadas à impressão que os novos professores têm da profissão. Estas impressões relacionam-se ao perfil dos alunos, às condições estruturais e de pessoal da escola e às relações interpessoais com os colegas de profissão. Os professores que assumiram turmas com alunos com deficiências, indisciplinados e dificuldades de aprendizagem, mas contaram com apoio da equipe pedagógica da escola e de seus colegas, e com um ambiente relativamente acolhedor, conseguiram realizar seu trabalho com mais tranquilidade e sem tanto sofrimento. Mas, se pelo contrário, às condições adversas une-se a questão da falta de experiência, a vontade de desistência e abandono da função surge com mais intensidade. Essas condições e situações são fatores bastante determinantes quando se pensa no bem ou mal estar dos professores iniciantes e no sucesso ou insucesso das primeiras experiências na profissão. Para os professores pesquisados, o início da carreira é um período em que necessitam "provar" aos outros, e a si mesmo, as suas competências como docentes.

Nesta pesquisa, procurou-se conhecer quais são as maiores dificuldades enfrentadas pelos professores iniciantes. Menos de $1 \%$ dos professores pesquisados informaram não sentir nenhuma dificuldade. Porém, a maioria, 99\%, apontam diversas dificuldades, as quais perpassam por questões pedagógicas, de infraestrutura e relacional. A ausência dos pais no processo educacional de seus filhos é uma constante queixa dos professores iniciantes, seguida por inúmeras "faltas", seja de material, espaço físico ou apoio. A questão salarial também está presente, assim como a necessidade de um novo Plano de Carreira do Magistério.

Por meio das respostas dos professores, pode-se dizer que as dificuldades dos professores iniciantes estão intrinsecamente ligadas às condições de trabalho que, segundo Oliveira (2010, p.12), 
possibilitam a realização do trabalho, envolvendo as instalações físicas, os materiais e insumos disponíveis, os equipamentos e meios de realização das atividades e outros tipos de apoio necessários, dependendo da natureza da produção.

As condições em que os professores exercem suas atividades influenciam diretamente nas suas vidas e nos resultados almejados como profissionais. Reconhecer algumas circunstâncias como sendo condições de trabalho, na maioria das vezes, é imperceptível aos governantes ou, quando detectadas, não se tornam alvo de ações que possam, de alguma forma, modificar esse cenário.

Vale ressaltar que condições de trabalho e condições salariais, embora distintas, caminham juntas. Os professores iniciantes buscam um sentido para aprenderem e se desenvolverem no trabalho realizado. Isso deveria promover satisfação a quem o realiza, para tanto, almejam melhores salários e condições de trabalho.

Cavaco (1991) considera que as condições iniciais da profissão docente causam alguma insegurança e instabilidade, podendo ser consideradas de sobrevivência, designação também utilizada por Huberman (1989), para caracterizar os professores no início de carreira afetados pelo choque com a realidade.

O trabalho docente pode ser considerado uma atividade difusa, a qual exige um planejamento prévio e constantes estudos. Além disso, algumas atribuições de ordem pedagógica e burocrática fazem parte da rotina docente, tais como: correção de trabalhos e avaliações, elaboração de relatórios, preenchimento de notas, entre outros. Esta intensificação de atribuições pode contribuir para a "desqualificação intelectual" do docente, pois, ao ter que cumprir mais essas tarefas, reduz o seu tempo disponível para estudos, participação em cursos ou outros recursos que possam contribuir para a sua qualificação e favorecer o seu desenvolvimento profissional. Além disso, diminui também o tempo destinado ao lazer, ao descanso e ao convívio social, pois muitas atividades são levadas para fazer em casa, fora do horário remunerado de trabalho.

\section{BREVES CONSIDERAÇÕES FINAIS}

O processo de inserção dos professores iniciantes tem-se constituído em um momento de grande importância na carreira do professor, não apenas por ser um 
período de adaptação à profissão docente, mas, sobretudo, pelas implicações dele decorrentes. Nesse processo, segundo os professores pesquisados, a recepção e integração com os novos colegas de trabalho e um adequado acompanhamento aos professores iniciantes é um importante fator para amenizar os desafios desse período. Muitos professores afirmaram que essa prática já vem sendo realizada pelas unidades escolares, porém como uma ação isolada, a qual depende do gestor escolar de cada unidade.

Os professores acreditam que escolas e Secretaria Municipal de Educação deveriam deixar "bem claras" as normas da rede, que orientassem sobre a matriz curricular e a condução do trabalho pedagógico. Também que possibilitassem situações de troca de experiências com os outros professores.

Embora a Secretaria de Educação afirme que tenha iniciativas de acompanhamento aos professores iniciantes através do estágio probatório, não se pode afirmar que esta ação seja, de fato "acompanhamento" como apoio efetivo aos professores iniciantes. Nesta direção, pode-se dizer que hoje a Secretaria Municipal de Educação não possui nenhuma ação articulada para a recepção e acolhimento dos professores iniciantes, muitos deles recém-saídos da graduação e tendo como experiência, na grande maioria, apenas o estágio supervisionado obrigatório na formação inicial.

Romanowski (2012) aponta alguns desafios para a promoção do desenvolvimento profissional dos professores iniciantes, dentre eles está o reconhecimento de que os professores iniciantes precisam de apoio quando iniciam sua atividade profissional e, por isso mesmo, a necessidade de se ter um programa de acompanhamento e supervisão destinados a promover o desenvolvimento profissional desses professores.

Por meio dos dados coletados, também se percebeu que se o ambiente e as condições de trabalho não forem adequados, a tendência é potencializar as possíveis dificuldades enfrentadas pelos professores em início de carreira, podendo causar desconforto e sofrimento, desencadeando, inclusive, a vontade de deixar a profissão. Ou seja, as dificuldades dos professores iniciantes estão intrinsecamente ligadas às suas condições de trabalho, as quais influenciam diretamente nas suas vidas e nos resultados almejados como profissionais. 
Os dados dos professores mostram que o início da docência é um período que requer uma aproximação com professores mais experientes, de um acompanhamento mais efetivo do trabalho que desenvolvem, de espaços adequados de formação continuada e de interlocução com os demais colegas professores e equipe administrativa. As vozes dos professores revelaram disponibilidade e receptividade para ações de formação e de desenvolvimento profissional.

Em síntese, a escola precisa se constituir em um espaço coletivo de formação que proporcione trocas de experiências, grupos de estudo e de uma supervisão que os direcione para a reflexão (teórica e prática) do fazer pedagógico.

É bastante complexo demonstrar os problemas do professor iniciante e apresentar um modelo de formação adequado, visando a sua qualificação, com o fim de superar seus dilemas nessa fase da carreira. Esse período se constitui por uma fase marcada por crises, e pode ser definido como o período de descoberta e de sobrevivência. Por isso, é imprescindível que a escola e o professor iniciante conversem muito e reflitam sobre as dificuldades e necessidades específicas do início da carreira. É fundamental que os profissionais da educação ofereçam apoio adequado a esse profissional.

\section{CLÁUDIA VALÉRIA GABARDO}

Mestre em Educação pelo Programa de Mestrado em Educação da Universidade da Região de Joinville (UNIVILLE). Professora do Departamento de Letras da UNIVILLE e da Rede Municipal de Ensino de Joinville.

\section{MÁRCIA DE SOUZA HOBOLD}

Doutora em Educação (Psicologia da Educação) pela Pontifícia Universidade Católica de São Paulo (PUC-SP). Professora do Departamento de Psicologia e do Programa de Mestrado em Educação da Universidade da Região de Joinville (UNIVILLE).

\section{REFERÊNCIAS}

ANDRÉ, M. E. D. A. Etnografia da prática escolar. Campinas: Papirus, 1995.

CAVACO, M. H. Ofício de professor: o tempo e as mudanças. In: NÓVOA, A. (Org.). Profissão Professor. Portugal: Porto, 1995. p. 84-107. 
FRANCO. M. L. P. B. Análise de Conteúdo. Brasília, $2^{a}$ edição; Líber Livros Editora, 2005

GATTI, B.; ANDRÉ, M. E. D. A. A relevância dos métodos de pesquisa qualitativa em Educação no Brasil. In: WELLER, Wivian; PFAFF, Nicolle (Orgs.). Metodologias da pesquisa qualitativa em educação: teoria e prática. Petrópolis, RJ: Vozes, 2010.

GONÇALVES, J. A. A carreira das professoras do ensino primário. In NÓVOA, A. (ed.). Vidas de Professores. Porto: Porto Editora, 1992.

HUBERMAN, M. O Ciclo de vida profissional dos professores. In: NÓVOA, A. (org.). Vidas de professores. 2. ed. Portugal: Porto Editora, 1992.

, M. O ciclo de vida profissional dos professores. In: NÓVOA, A. (Org.).Vidas de professores. 2 ed. Portugal: Porto Editora, 1992.

LAKATOS, E. M. e MARCONI, M. A. Fundamentos da Metodologia Científica. $5^{a}$. ed. São Paulo: Atlas, 2003.

LIMA, E. F.(Org.) Sobrevivências no início da docência. Brasília: Líber Livro, 2006.

LÜDKE, M. Sobre a socialização profissional de professores. Cadernos de Pesquisa n 99, 1996, p. 5-15.

LÜDKE, M. Os professores e sua socialização profissional. In: REALI, A M. M. R., MIZUKAMI, M. G. N. (Org.) Formação de professores: Tendências Atuais. São Carlos, SP: EDUFSCar, p.25-46,1996.

MARCELO GARCIA, C. Formação de Professores - para uma mudança educativa. Coleção Ciências da Educação. Porto - Portugal: Porto Editora LDA, 1999.

C. A formação de professores: centro de atenção e pedra-detoque. In: NÓVOA, A. (Coord.). Os professores e sua formação. Lisboa: Dom Quixote, 1992. p. 53-76.

MAY, T. Pesquisa Social.: Questões, Métodos e Processos. Porto Alegre: Artmed, 2004.

MONTEIRO VIEIRA, H. M. Como vou aprendendo a ser professora depois da formatura: análise do tornar-se professora na prática da docência. 2002. 197f. Tese (Doutorado em Educação) - Universidade Federal de São Carlos, São Carlos, 2002.

OLIVEIRA, D. A. A reestruturação do trabalho docente: precarização e flexibilização. Educ. Soc. [online]. 2004, vol.25, n.89, p. 1127-1144. ISSN 01017330.

OLIVEIRA, D. A; ASSUNÇÃO, A. Á. Intensificação do trabalho e saúde dos 
professores. Educação e Sociedade, Campinas, vol. 30, n. 107, p. 349-372, maio/ago. 2009.

. Condições de trabalho docente. In: OLIVEIRA, Dalila Andrade; DUARTE, Adriana Cancella; VIEIRA, Lívia Fraga (Org.). Dicionário trabalho, profissão e condição docente. Belo Horizonte: Ed. da UFMG, 2010. 1 CD-ROM.

PAPI, S. de O. G.; MARTINS, P. L. O. As pesquisas sobre professores iniciantes: algumas aproximações. Educação em Revista. Belo Horizonte. V.26 n.3, 2010

ROMANOWSKI, J. P. Formação e profissionalização docente. $3^{a}$ ed. rev. e atual. Curitiba: ibpex, 2007.

J. P. As licenciaturas no Brasil: um balanço das teses e dissertações

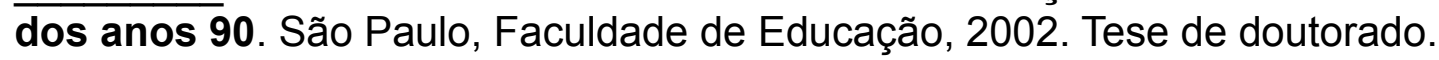

. Professores principiantes no Brasil: questões atuais. In: III CONGRESSO INTERNACIONAL SOBRE PROFESORADO PRINCIPIANTE E INSERCIÓN PROFESIONAL A LA DOCENCIA, Santiago do Chile, 2012.

TARDIF, M. Saberes docentes e formação profissional. Petrópolis, RJ: Vozes, 2002.

VEENMAN, S. Perceived Problems of beginning teachers. In: Review of Educactional Research Summer, v.54, n.2, 1984, p.143-178. In: SOUZA, Dulcinéia Beirigo de1 Os dilemas do professor iniciante: reflexões sobre os cursos de formação inicial, Revista Multidisciplinar da UNIESP, nº 08, Dez. 2009/ISSN 19805950.

Disponível

em:

http://www.uniesp.edu.br/revista/revista8/pdf/artigos/04Pdf.Acesso em 18/05/2011 